\title{
Green Synthesis of Silver Nanoparticles by Sonicated Method using Pulicha indeca Stem Extract: Characterization Antibacterial and Anticancer Activity and Cell Viability Test
}

\author{
GUGULOTHU YAKU1', VENKATESWERLU² and TVD PRASAD RAO ${ }^{3 *}$ \\ ${ }^{1-3}$ Department of Chemistry, Osmania University, Hyderabad-500 007, Telangana State, India. \\ ${ }^{*}$ Corresponding author E-mail: thyp123@gmail.com \\ http://dx.doi.org/10.13005/ojc/350620
}

(Received: November 02, 2019; Accepted: December 04, 2019)

\begin{abstract}
In the present work, green synthesized silver nanoparticles by sonofication method using Pulicha indeca extract, which can act as reducing as well as stabilizing agent. The silver nanoparticles were characterized by UV-Vis spectra, FTIR, XRD, SEM and TEM analysis. The UV-Vis SPR peak was observed at $440 \mathrm{~nm}$, which represents the characteristic plasmon resonance of nanostructures. The F.C.C crystalline structure of silver nanoparticles is evident from XRD studies. The shape and size of synthesized AgNPs were studied by TEM. The synthesized AgNPs, were mostly mono-dispersed and spherical in shape. The particles are well separated from each other and did not exhibit any aggregation. This indicates the effective capping nature of Pulchea indeca extract. The AgNPs size distribution histogram and the average size of AgNPs was found to be $14 \pm 2 \mathrm{~nm}$. The effect of silver ion concentration range from $1 \mathrm{~mm}$ to $10 \mathrm{~mm}$ and extract concentration $1 \%$ to $8 \%$ has been studied on the formation of silver nano particles. The AgNPs shows positive antibacterial acivity against Stayphylococus aureous, Klebisella pneumonia, Bacillus subtilis and negative antibacterial activity against Protious mirabilis bacteria studies. The anticancer activity of AgNps shows positive activity on HeLa cell.
\end{abstract}

Keyword: Green synthesis, Silver nanoparticles, Antibacterial activity.

\section{INTRODUCTION}

Silver nanoparticles (AgNPs) are widely applicable in pharmaceuticals, health care industrial and consumer care etc. due to their specific physical and chemical features ${ }^{1-3}$, Owing to specific features of silver nanoparticles, they are used as antibacterial agents, s and anti-cancer (agents) drugs ${ }^{4}$. Silver nanoparticles have been used in textiles, biomedical, domestic ${ }^{2,5,6}$. Silver nanoparticles are unique in nature due to its surface to volume ratio, hence they can be used in different applications ${ }^{7,8}$.

Nanoparticles are important in pharmaceutical industries and bio technological industries. Silver nanoparticles exhibits antibacterial, anticancer, antifungal, anti plasmodial and anti larvacidal properties ${ }^{9-13}$. Silver nanoparticles are less toxic to animal cells.and most efficient anti bacterial activity.

This is an Open Access article licensed under a Creative Commons license: Attribution 4.0 International (CC- BY). Published by Oriental Scientific Publishing Company @ 2018 
For the synthesis of AgNps different methods ${ }^{14,16-18}$ have been adopted. The conventional physical and chemical methods are more cost effective and harmfull. Generally, chemical stabilizers ${ }^{18-22}$ can be used for in the synthesis of AgNps. However, some of chemical stabilizers are toxic and able to pollute the environment.

The green chemistry exhibits much interest for the synthesis of silver nanoparticles. In different biological synthesis methods, of the AgNps, are having definite size and morphology. Sincere efforts are made to synthesise nanoparticles using natural products as stabilisers ${ }^{14,15,17}$ and plant extracts ${ }^{23,24}$ as stabilizing agent. Hydroxy groups in natural products can act as reducing as well as stabilisiing agents.

Cancer is multi factoial desease, that is treated by various treatments including chemotherapy, surgery, radiation, and targeted therapy ${ }^{25}$. So the challenge is cost effective, cell targeted AgNps can be synthesized for the therapeutic usage as antcancer agent drugs.

In the present work synthesized AgNps, using pulichea indeca extract which can act as reducing as well as stabilizing agent. The AgNps are characterized by using different techniques. The anti bacterial activity and anti cancer activity for the AgNps have been studied. Finally these studies gives future perspective for the AgNps.

\section{MATERIALS AND METHODS}

Fresh and healthy of pulchea indica stems were collected from the local area near mancheryala, adilabad (dist), TS India. A. R Grade (99.9\%) of Silver Nitrate (Merck. India) and The Cancer cell lines from NCCS, Pune, were purchased In this study DD $\mathrm{H}_{2} \mathrm{O}$ is used as solvent for further sample analysis.

\section{Methods \\ Preparation of pulchea indeca extract}

About $10 \mathrm{~g}$ of pulchea indeca stem cleaned with tap water followed by $\mathrm{DD} \mathrm{H}_{2} \mathrm{O}$ and then stems were collected. The washed stems are thoroughly dried under sun light to remove hygroscopic (unwanted material) nature from the stems. Further the dried stems were chopped into small species and grinded to get the fine powder. Nearly $10 \mathrm{~g}$ of fine powder is added to $250 \mathrm{~mL}$ of $\mathrm{DD} \mathrm{H}_{2} \mathrm{O}$ and heated by using magnetic stirrer. After continuous stirring for $30 \mathrm{~min}$ at $120^{\circ} \mathrm{C}$, the extract was filtered at 6000 $\mathrm{rpm}$. The extract is stored at $5^{\circ} \mathrm{C}$ for further usage.

\section{Synthesis of AgNPs}

For the Synthesis of AgNPs, different samples were prepared by mixing $20 \mathrm{~mL}$ of $\mathrm{AgNO}_{3}$ solutions having concentration from $0.1 \mathrm{mM}$, to $1.0 \mathrm{mM}$ each with $60 \mathrm{~mL}$ of pulchea indeca extract. And $60 \mathrm{~mL}$ of $1 \%$, 2\%, 3\%, 4\%, 5\% 6\%, 7\% and $8 \%$ stem extract solutions are mixed each with $20 \mathrm{~mL}$ of $\mathrm{AgNO}_{3}$ solution.

\section{Characterization}

After color change of AgNps solutions, the synthesized AgNps were analyzed by measuring the Surface Plasmon Resonance (SPR) at a wavelength range between 200 and $800 \mathrm{~nm}$ by the UV Spectroscopy FT-IR spectra for Stem extract alone and stem capped AgNPs were recorded separately by using an FT-IR spectrophotometer. Powder X-ray Diffraction (XRD) measurements AgNPs were carried out in X'pert Pro-powder X-ray diffractometer. The morphology and size distribution measurements of the AgNPs were carried out by (HR-TEM, FEl Company, USA).

\section{Antibacterial activity test}

The synthesized AgNps solution were taken and made into aliquots of $25 \mu \mathrm{l}, 50 \mu \mathrm{l}, 75 \mu \mathrm{l}, 100 \mu \mathrm{l}$ by dissolving them in DMSO (solvent) for MIC assay in case of powdered samples and for liquid samples used directly.

\section{Antibacterial assay}

The antibacterial assay was carried out by performing pour plate method in which $1 \mathrm{~mL}$ bacterial active cultures per plate were mixed into agar media before solidifying temperature and poured into plates. Wells were made by using sterile well borer and samples loaded $25 \mu \mathrm{l} 50 \mu \mathrm{l} 75 \mu \mathrm{l} 100 \mu \mathrm{l} \mu \mathrm{l}$ of each respectively, in Gram-positive and Gram-negative plates. Plates were incubated at $37^{\circ} \mathrm{C}$ degrees for 36 hours. In antibacterial study, four Gram-positive and Gram-negative bacteria (a) Staphylococcus aureous (Gram-positive), (b) Klebsiella eumoniae, (Gramnegative) (c) Bacillus subtitles (Gram-positive), and (d) Proteus mirabilis (Gram-negative) were used. 


\section{RESULTS AND DISCUSSION}

\section{UV-Vis Spectroscopy}

The UV-Vis spectrum of synthesized AgNPs showed the absorption peak at $440 \mathrm{~nm}$ indicated the formation of Nano metallic silver particles. Pulchea indeca stem extract contains flavonoids, alkaloids and proteins could reduce silver ions in the reaction solution and stabilizes the synthesized AgNPs. The formation of pulchea indeca -AgNPs was confirmed by a colour change from colorless to yellow color. A sharp and a narrow distinct peak are absorbed at $\lambda_{\text {max }}$ $=440 \mathrm{~nm}$ in the ultra-visible region, clearly elucidates the formation of AgNPs within a short duration of time (10-15 min). The role of pulchea indeca concentration and $\mathrm{AgNO}_{3}$ concentrations, were studied over the synthesis of AgNps. Fig.1a shows the effect of $\mathrm{AgNO}_{3}$ concentrations $(0.1 \mathrm{~mm}$ to $1.0 \mathrm{mM}$ on the synthesis AgNps. The effect has been studied by sonication method using different concentrations of $\mathrm{AgNO}_{3}$ $(0.1-0.10 \%)$ mixed with $5 \%$ of plant extract of pulchea indeca for $15 \mathrm{~min}$ of time (1:3 ratio) and it indicates the formation of AgNPs increases with increasing the concentration of $\mathrm{AgNO}_{3}$. This may be due to increase in the number of silver ions with the increase in concentration of $\mathrm{AgNO}_{3}$. Absorption spectra of AgNPs prepared at different pulchea indeca concentration are presented in Fig.1b. It reveals that the AgNPs increases with the increases concentration of the pulchea indeca. The synthesis was also evaluated by mixing different concentration of pulchea indeca (1\% to $8 \%$ ) with $0.5 \mathrm{mM}$ concentration of $\mathrm{AgNO}_{3}$ (3:1 ratio) for 15 min time (Fig.1b). With the increase in the concentration of pulchea indeca plant extract from $1 \%$ to $8 \%$, the SPR absorption band intensities are increased. This may be due to availability number of flavonoids, alkaloids and proteins in the extract are reducing more number of silver ions into more number of silver nanoparticles.

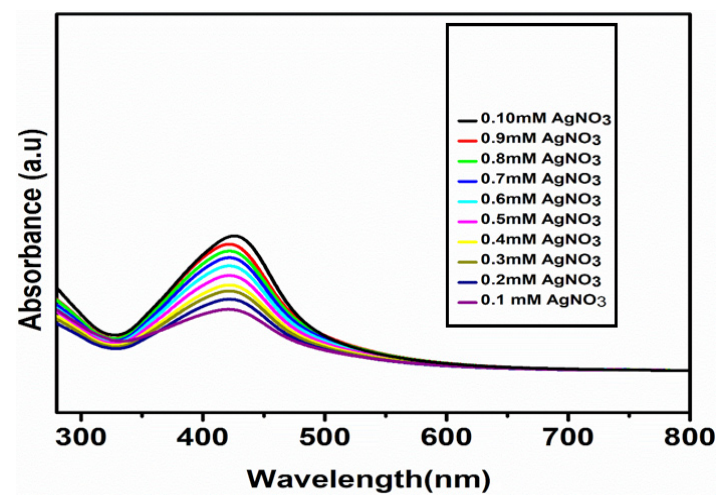

Fig. 1 (a). UV-Visible spectra of AgNPs showing the (a) effect of $\mathrm{AgNO}_{3}$ concentration on the formation of AgNPs

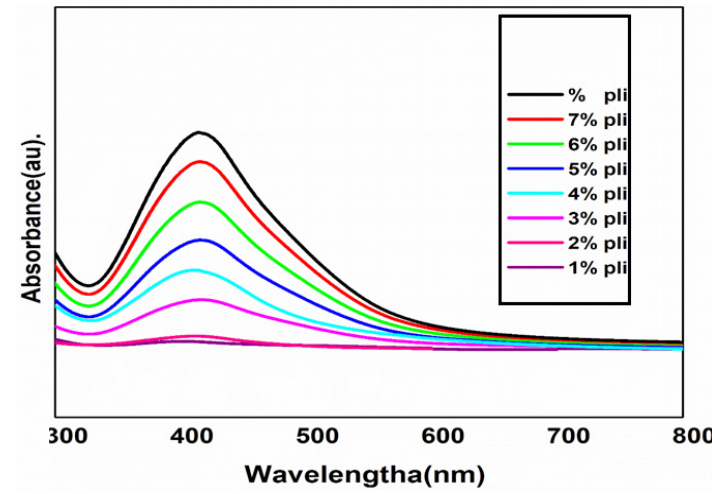

Fig. 1(b). UV-Visible spectra of AgNPs showing the effect effect of pulchea indeca plant extracts concentration on the formation of AgNPs

\section{FTIR analysis of AgNPs}

FTIR studies was carried out to analyse the pulchea indeca extract alone and the capping/ stabilized AgNPs which are formed by the reduction of silver ions of $\mathrm{AgNO}_{3}$ with the flavonoids, alkaloids and proteins present in the pulchea indeca extract The FTIR spectra of pulchea indeca extract alone (Fig. 2b) exhibited stretching vibrations at 3300, 2940, 1750,1360 and $1011 \mathrm{~cm}^{-1}$, while the pulchea indeca extract capped/stabilized AgNPs (Fig. 2a) shows the characteristic stretching frequencies at 3340, 2953, $1745,1610,1360$ and $1020 \mathrm{~cm}^{-1}$. The broad peak at around $3300 \mathrm{~cm}^{-1}$ in figure a corresponds to the $-\mathrm{OH}$ stretching vibrations of flavonoids. The peak at around $2940 \mathrm{~cm}^{-1}$ belongs to $-\mathrm{CH}$ stretching, and strong peak at around $1750 \mathrm{~cm}^{-1}$ can be assigned to the carbonyl stretching. Further the peaks at around $1011 \mathrm{~cm}^{-1}$ can elucidate to the $\mathrm{C}-\mathrm{O}$ stretching. FTIR spectra of pulchea indeca extract capped/stabilized AgNPs shows some clear individual from that of FTIR spectra of pulchea indeca extract alone. Most importantly, the intensity of $-\mathrm{OH}$ stretching vibration is reduced and the intensity of carbonyl stretching got increased.

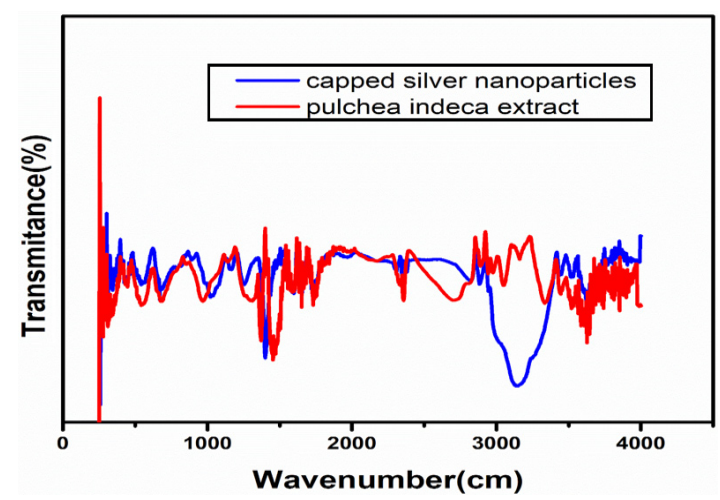

Fig. 2. FTIR spectra of (a) pulchea indeca capped AgNPs and (b) pulchea indeca alone 


\section{XRD analysis of AgNPs}

The XRD pattern of AgNPs Fig. 3 using pulchea indeca extract and peelings extract capped AgNPs were carried out by coating the colloidal stable samples under the reduced pressure. In the XRD spectrum, the Bragg peaks at $2 \theta=33.2^{\circ}, 48.5^{\circ}, 65.6^{\circ}$ and $78.8^{\circ}$ for $111,200,220,311$ planes were identified the crystalinity of pulchea indeca extract capped AgNPs Fig. 3. These values agreed with reported fcc crystalline silver nanoparticles. The X-ray diffraction studies indicate the presence of phytochemicals in the pulchea indeca extract solution.

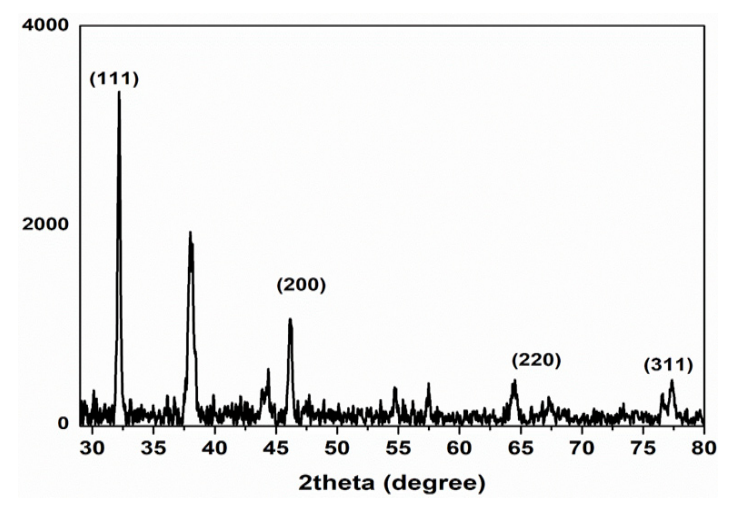

Fig. 3. XRD spectra of a capped AgNPs

\section{Surface Morphological Study (FE-SEM)}

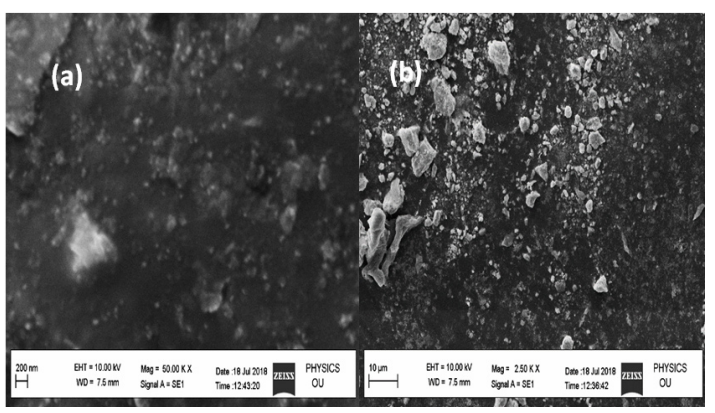

Fig. 4. (a) and (b) FE-SEM images of AgNPs

Morphology of AgNPs were studied from FE-SEM images from the FE-SEM images of the Ag nanoparticle are nearly spherical shape. There were a few Ag nanoparticles having oval shape as well. According to these studies, maximum number of the nanoparticles is having an average diameter and size is less than $50 \mathrm{~nm}$. It indicates that maximum nanoparticles are uniform in nature and these Nano-particles were formed by Sonicated assisted green method. The size distribution of 25-40nm and an average diameter about $14 \pm 2 \mathrm{~nm}$ of silver nanoparticles, indicates that AgNPs were bio-synthesized by using dried pulchea indeca extract. According to EDX spectrometers analysis the presence of the elemental Ag signals, corresponding to the Ag nanoparticles were confirmed.

\section{Surface Morphological Study (EDX)}

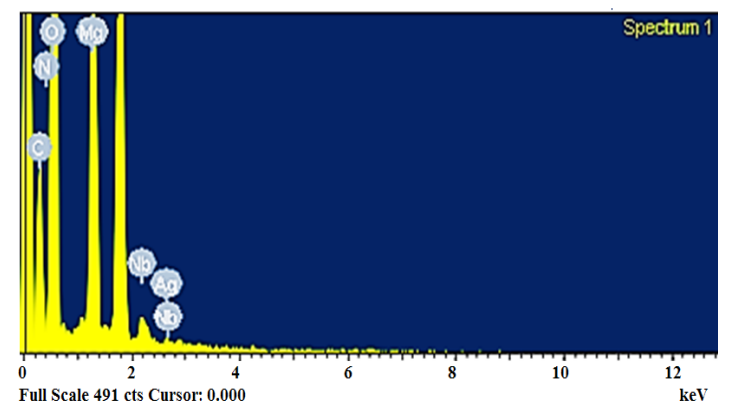

Fig. 4(c). FE- SEM image of AgNPs, EDX

TEM images of AgNps and particle size distribution
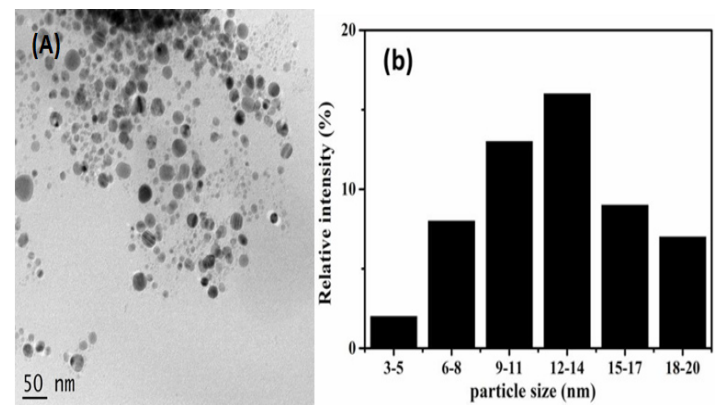

Fig. 5(a). TEM image of Ag NPs, (b) particle size distribution of AgNps

The shape and size of synthesised AgNPs were studied by TEM. The Fig. $5 \mathrm{a}$ shows that synthesized AgNPs, were mostly mono-dispersed and spherical in shape. The particles are well separated from each other and did not exhibit any aggregation. This indicates the effective capping nature of pulchea indeca extract. The histogram AgNPs size distribution of (Fig. 5b) was constructed and the average size of AgNPs was found to be $14 \pm 2 \mathrm{~nm}$.

\section{Antibacterial activity of silver nanoparticles.}

The antibacterial activity of AgNPs was studied against a) Staphylococcus aureus (Gramnegative), b) Bacillus subtilis (Gram-positive), c) Klebsiella pneumoniae (Gram-negative) and d) Protious mirabilis (Gram-negative) by agar well diffusion method (Fig.6). The zone of inhibition of four bacteria for AgNps are given in Table (1) the AgNPs are directly binded with DNA structure 
of Gram-negative bacteria and it ruptures and deform the structure and thus, kills bacteria. Green Synthesized AgNPs shows better antibacterial activity for silver nanoparticles, which makes contact with a greater amount of bacteria and destruct the bacteria. As calculated from structural study, better antibacterial activity is obtained at $100 \mathrm{~mL}$ of prepared AgNPs against all four bacteria studied. Thus, all the factors shows good antibacterial activity for synthesized AgNPs.

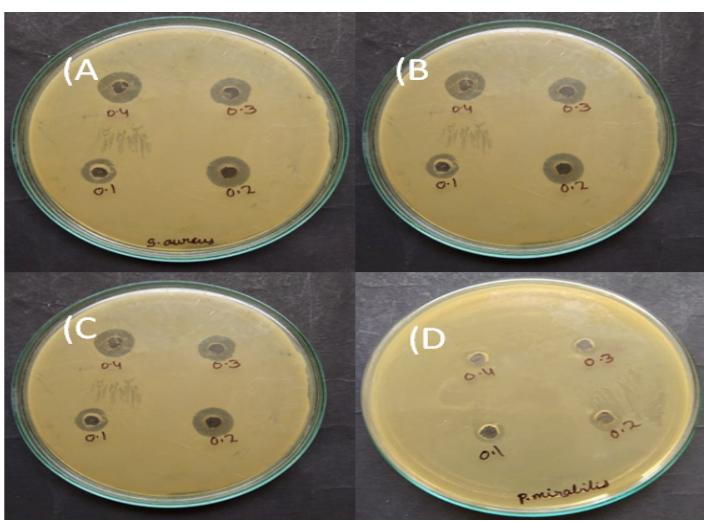

Fig. 6. Antibacterial activity of pulchea indeca extract capped AgNPs using (a) Stayphylococusaureoous b) Klebisellapneumonia, c) Basilusbtilis, d) protious mirabilis

Table 1: Zone of inhibition (in $\mathrm{cm}$ ) for the bacteria at different concentration of the AgNps

\begin{tabular}{cccccc}
\hline S.no & Name of bacteria & $25 \mu \mathrm{l}$ & $50 \mu \mathrm{l}$ & $75 \mu \mathrm{l}$ & $100 \mu \mathrm{l}$ \\
\hline 1 & Stayphylococus & & & & \\
& aureoous & 0.2 & 0.3 & 0.3 & 0.4 \\
2 & Bacillussubtilis & 0.3 & 0.4 & 0.4 & 0.6 \\
3 & Klebsiella pneumoniae & 0.3 & 0.6 & 0.6 & 0.8 \\
4 & protious mirabilis & - & - & - & - \\
\hline
\end{tabular}

\section{Anti-cancer activity}

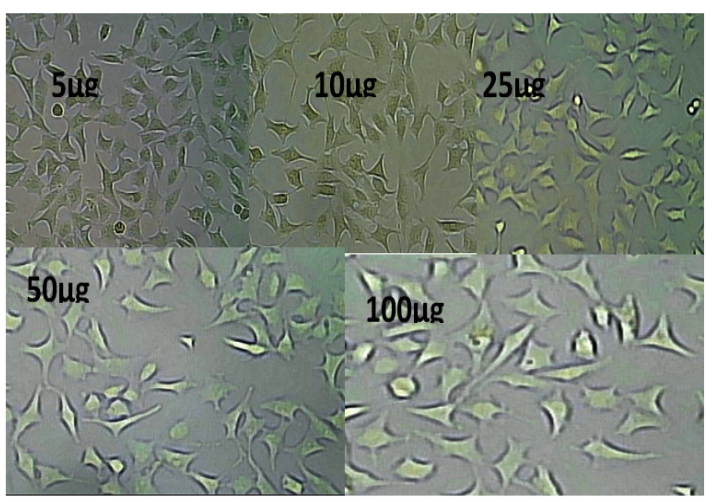

The anti cancer activity of test compounds are determined by using MTT assay.
Table 2: Absorbance, percentage of inhibition, \% of viability and $\mathrm{IC}_{50}$ values at different concentration of silver nanoparticles in the study of anticancer activity Concentration Absorbance \%Inhibition \%Viability $\mathrm{IC}_{50}(\mathrm{\mu g})$ $(\mu \mathrm{g}) \quad$ at $570 \mathrm{~nm}$

\begin{tabular}{ccccc}
\hline 5 & 0.552 & 24.59 & 75.41 & \\
10 & 0.421 & 42.48 & 57.52 & \\
25 & 0.352 & 51.91 & 48.09 & \\
50 & 0.302 & 58.74 & 41.26 & \\
100 & 0.317 & 57.37 & 42.63 & \\
Untreated & 0.732 & 0 & 100 & 49.34 \\
Blank & 0 & 0 & 0 & \\
\hline
\end{tabular}

Measurement of cell viability and proliferation forms the basis for numerous in vitro assays of a cell population's response to external factors. The MTT Cell Proliferation Assay measures the cell proliferation rate and conversely, when metabolic events lead to apoptosis or necrosis, the reduction in cell viability.

\section{Cell viability test}

The AgNps has anti cancer activity (49.34) against Hela cell at $100 \mu \mathrm{g}$ concentration of silver nanoparticles.

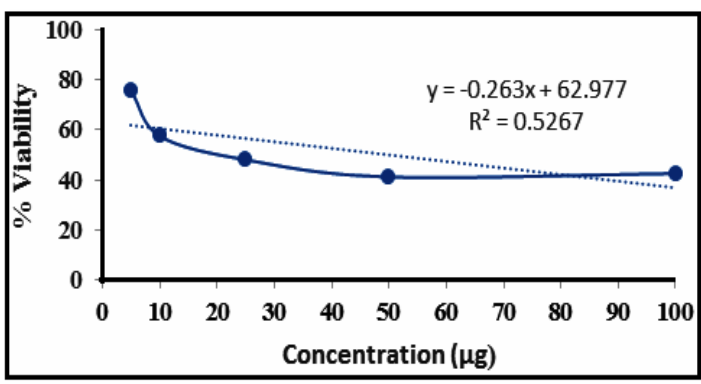

Table 3: Test compounds treated with HeLa cells showing the $\mathrm{IC}_{50}$ values are as shown in the table

\begin{tabular}{ccc}
\hline S. no & Sample name & $\mathrm{IC}_{50}(\mu \mathrm{g}) \mathrm{HeLa}$ \\
\hline 1 & AgNPs $100 \mu \mathrm{g}$ & 49.34 \\
\hline
\end{tabular}

\section{CONCLUSION}

Then synthesis of stable AgNPs was achieved without adding any external reagents. It is efficient and eco-friendly renewable "green" approach has been established for the green synthesis of AgNPs. The synthesis is carried out using DD $\mathrm{H}_{2} \mathrm{O}$, Pulchea indeca plant extract with sonicated method. The Pulchea indeca plant extract used as a reducing/stabilizing agent without using any harmful 
chemicals and synthetic reagents. The concentration of pulchea indeca plant extract and concentration of $\mathrm{Ag} \mathrm{NO}_{3}$ solutiion affected the amount of formation of AgNPs. The antibacterial activity studies of AgNPs reveals that the synthesized AgNPs shows positive antibacterial activity against Staphylococcus aureus (Gram-negative), Bacillus subtilis (Gram-positive) and Klebsiella pneumoniae (Gram-negative) bacteria. Synthesised AgNPs shows nagative antibacterial activity against protious mirabilis (Gram-negative) bacteria the silver nanoparticles exibits positive anticancer activity against Hela cancer cells (49.34). Such cheap source of material gives an opportunity to a cost-effective and ecofriendly preparation of stable AgNPs having various potential applications to be used.

\section{ACKNOELEDGEMENT}

Y. G. gratefully acknowledges Rajiv Gandhi National Fellowship. The authors acknowledge DSTFIST, and the authors are thanks full to MRC, MNIT Jaipur, STICK Cochin Kerala for extending various analytical facilities and my sincere thanks to $\mathrm{Dr}$. Nagamani. P, Department of Microbiology, Osmania University for providing an antibacterial activity and my heart full thanks to Dr. Rajkumar. Bandi, postdoc fellow at South Korea, Forest Science Department Authors are Sincere thanks full to Department of Chemistry, and CFRD-OU.

\section{Conflict of Interest} in this writing.

The authors declare no conflict of interest

\section{REFERENCES}

1. Gurunathan, S.; Park, J.H.; Han, J.W.; Kim, J.H. Comparative assessment of the apoptotic potential of silver nanoparticles synthesized by Bacillus tequilensis and Calocybe indica in MDA-MB-231 human breast cancer cells: Targeting p53 for anticancer therapy. Int. J. Nanomed., 2015, 10, 4203-4222.

2. Li,W.R.; Xie, X.B.; Shi, Q.S.; Zeng, H.Y.; OuYang, Y.S.; Chen, Y.B. Antibacterial activity and mechanism of silver nanoparticles on Escherichia coli. Appl. Microbiol. Biotechnol., 2010, 8, 1115-1122.

3. Mukherjee, P.; Ahmad, A.; Mandal, D.; Senapati, S.; Sainkar, S.R.; Khan, M.I.; Renu, P.; Ajaykumar, P.V.; Alam, M.; Kumar, R.; Fungus-mediated synthesis of silver nanoparticles and their immobilization in the mycelial matrix: A novel biological approach to nanoparticle synthesis. Nano Lett., 2001, 1, 515-519.

4. Chernousova, S.; Epple, M. Silver as antibacterial agent: Ion, nanoparticle, and metal. Angew. Chem. Int. Ed., 2013, 52, 1636-1653.

5. Li, C.Y.; Zhang, Y.J.; Wang, M.; Zhang, Y.; Chen, G.; Li, L.; Wu, D.; Wang, Q. In vivo real-time visualization of tissue blood flow and angiogenesis using $\mathrm{Ag}_{2} \mathrm{~S}$ quantum dots in the NIR-II window. Biomaterials., 2014, 35, 393-400.

6. Sondi, I.; Salopek-Sondi, B. Silver nanoparticles as antimicrobial agent: A case study on E. coli as a model for Gram-negative bacteria. J.
Colloid Interface Sci., 2004, 275, 177-182.

7. Li, L.; Hu, J.; Yang, W.; Alivisatos, A.P. Band gap variation of size- and shape-controlled colloidal CdSe quantum rods. Nano Lett., 2001, 1, 349-351.

8. Sharma, V.K.; Yngard, R.A.; Lin, Y. Silver nanoparticles: Green synthesis and their antimicrobial activities. Adv. Colloid Interface., 2009, 145, 83-96.

9. Gurunathan S., Park J.H., Han J.W., Kim J.H. Comparative assessment of the apoptotic potential of silver nanoparticles synthesized by Bacillus tequilensis and Calocybe indica in MDA-MB-231 human breast cancer cells: Targeting p53 for anticancer therapy. Int. J. Nanomed., 2015, 10, 4203-4222. doi: 10.2147/IJN.S83953.

10. Li W.R., Xie X.B., Shi Q.S., Zeng H.Y., OuYang Y.S., Chen Y.B. Antibacterial activity and mechanism of silver nanoparticles on Escherichia coli. Appl. Microbiol. Biotechnol., 2010, 8, 1115-1122. doi: 10.1007/s00253009-2159-5.

6. Mukherjee P., Ahmad A., Mandal D., Senapati S., Sainkar S.R., Khan M.I., Renu P., Ajaykumar P.V., Alam M., Kumar R., Fungusmediated synthesis of silver nanoparticles and their immobilization in the mycelial matrix: A novel biological approach to nanoparticle synthesis. Nano Lett., 2001, 1, 515-519. doi: 10.1021/nl0155274. 
11. Chernousova S., Epple M. Silver as antibacterial agent: Ion, nanoparticle, and metal. Angew. Chem. Int. Ed., 2013, 52, 1636-1653. doi: 10.1002/anie.201205923.

12. Li C.Y., Zhang Y.J., Wang M., Zhang Y., Chen G., Li L., Wu D., Wang Q. In vivo realtime visualization of tissue blood flow and angiogenesis using $\mathrm{Ag}_{2} \mathrm{~S}$ quantum dots in the NIR-II window. Biomaterials., 2014, 35, 393400. doi: 10.1016/j.biomaterials. 2013.10.010.

13. Sondi I., Salopek-Sondi B. Silver nanoparticles as antimicrobial agent: A case study on E. coli as a model for Gram-negative bacteria. J. Colloid Interface Sci., 2004, 275, 177-182. doi: 10.1016/j.jcis.2004.02.012

14. Z. Li, Y. Wang, Q. Yu, Significant parameters in the optimization of synthesis of silver nanoparticles by chemical reduction method, J. Mater. Eng. Perform., 2010, 19, 252-256.

15. S. Kheybari, S.V. Hosseini, A. Fazeli, M.R. Fazeli, Synthesis and antimicrobial effects of silver nanoparticles produced by chemical reduction method, DARU., 2010, 18, 168-172.

16. K. Song, S. Lee, T. Park, B. Lee, Preparation of colloidal silver nanoparticles by chemical reduction method, Korean J. Chem. Eng., 2009, 26, 153-155.

17. T. Kempa, R. Farrer, M. Giersig, J. Fourkas, Photochemical synthesis and multiphoton luminescence of monodisperse silver nanocrystals, Plasmonics., 2006, 1, 45-51.

18. P.K. Sahoo, S.S. Kalyan Kamal, T.J. Kumar, B. Sreedhar, A.K. Singh, S.K. Srivastava, Synthesis of silver nanoparticles using facile wet chemical route, Def. Sci. J., 2009, 59 (4).

19. J.-K. Liu, X.-H. Yang, X.-G. Tian, Preparation of silver/hydroxyapatite nanocomposite spheres, Powder Technol., 2008, 184, 21-24.

20. K. Song, S. Lee, T. Park, B. Lee, Preparation of colloidal silver nanoparticles by chemical reduction method, Korean J. Chem. Eng., 2009, 26, 153-155.

21. C. Kan, C. Wang, J. Zhu, H. Li, Formation of gold and silver nanostructures within polyvinylpyrollidone (PVP) gel, J. Solid State Chem., 2010, 183, 858-865.

22. G. Carotenuto, Synthesis and characterization of poly(N-vinylpyrrolidone) filled by monodispersed silver clusters with controlled size, Appl. Organomet. Chem., 2001, 15, 344-351.

23. R.D. Rivera-Rangel, M.P. González-Muñoz, M. Avila-Rodriguez, T.A. Razo-Lazcano, C. Solans, Green synthesis of silver nanoparticles in oilin-water microemulsion and nanoemulsion using geranium leaf aqueous extract as a reducing agent, Colloids Surf. $A$ Physicochem. Eng. Asp., 2018, 536, 60-67.

24. H. Veisi, S. Azizi, P. Mohammadi, Green synthesis of the silver nanoparticles mediated by Thymbra spicata extract and its application as a heterogeneous and recyclable nanocatalyst for catalytic reduction of a variety of dyes in water, J. Clean. Prod., 2018, 170, 1536-1543.

25. American Cancer Society. Cancer Facts \& Figures 2015; American Cancer Society: Atlanta, GA, USA., 2015. 